\title{
Dimension of Customer Satisfaction in the Hotel Business
}

\author{
S. Jayakanth and Dr.B. Adalarasu
}

\begin{abstract}
Customer Satisfaction is the key Challenges for the Hotel Business, because it is unpredictable and customer interest towards food is keep on changing. Hence Providing Customer satisfaction and maintaining it to the greatest extent is a typical task for the Hotel owners. In the competitive scenario, it is very hectic task to differentiate the service quality among the competitors in order to retain the existing customers. The vast development in the Indian tourism sector customer expectation on quality food products and hygienic services in the current trend has moved to professionalism. Successful businesses evidence the match between customer demand and service quality. The Objective of this research is to identify the traveller's comments and their satisfaction in the selected leading hotels. The researcher expects that this study will ensure the professionalism followed in the hotel business and estimates the methods followed in the hotel business for customer satisfaction.
\end{abstract}

\section{INTRODUCTION}

$\mathrm{I}$ $\mathrm{N}$ the past few decades, customer satisfaction and service quality become a key area of consideration by the practitioners and scholastic researchers. Both concepts have strong impact on the business performance and customer behaviour. Service Quality leads to higher profitability (Gundersen et al., 1996) and Customer Satisfaction (Oliver, 1997). Furthermore, a number of empirical studies indicate a positive relationship between the customer satisfaction and the customer loyalty (Kandampully and Suhartanto, 2000; Dimitriades, 2006; Chi and Qu, 2008; Faullant et al., 2008), as well as between the customer satisfaction and positive wordof-mouth (Söderlund, 1998). Therefore, one of the key strategies for customer-focused firms is to measure and monitor the service quality and the customer satisfaction

\section{REVIEW OF LITERATURE AND CONCEPT}

Customer satisfaction is a well-liked topic in marketing practice and academic research since Cardozo's (1965) initial study of the customer effort, expectations and satisfaction. Despite many attempts is to made measure and explain the customer satisfaction, but it doesnot appear as consensus regarding its definition (Giese and Cote, 2000).

Customer satisfaction is typically defined as a post consumption evaluative judgement concerning a specific product or service (Gundersen, Heide and Olsson, 1996). It is

S. Jayakanth, Research Scholar, Karpagam University. Coimbatore, Tamil Nadu.

Dr.B. Adalarasu, Dean, RVS Faculty of Management, Kumaran Kottam Campus, Kannampalayam, Coimbatore, Tamil Nadu.

DOI:10.9756/BIJIEMS.8304 the result of an evaluative process that contrasts pre purchase expectations with the perceptions of performance during and after the Consumption experience (Oliver, 1980).

The commonly accepted conceptualization of the customer satisfaction concept is the expectancy disconfirmation theory (Barsky, 1992; Oh and Parks, 1997; McQuitty, Finn and Wiley, 2000). The theory was developed by Oliver (1980), who proposed that satisfaction level is a result of the difference between expected and perceived performance. Satisfaction (positive disconfirmation) occurs when product or service is better than expected. On the other hand, the performance is worser than the expected results with dissatisfaction (negative disconfirmation).

The studies show that the customer satisfaction may have direct and indirect impact on business results.

Anderson et al. (1994), Yeung et al. (2002), and Luo and Homburg (2007) conclude that the customer satisfaction positively affects the business profitability. The majority of studies explore the relationship with customer behaviour patterns (Söderlund, 1998; Kandampully and Suhartanto, 2000; Dimitriades, 2006; Olorunniwo et al., 2006; Chi and Qu, 2008; Faullant et al., 2008). According to these findings, the customer satisfaction increases the customer loyalty, which influences repurchase intentions and leads to positive word-ofmouth.

The vital role of customer satisfaction given, it is not surprising a variety of research is devoted to examine the determinants of satisfaction (Churchill and Surprenant, 1982; Oliver, 1980; Barsky, 1995; Zeithaml and Bitner, 2003). Satisfaction can be determined by subjective (e. g. customer needs, emotions) and objective factors (e. g. product and service features). Applying to the hospitality industry, numerous studies are attempted. It observes that travelers may find important regarding the customer satisfaction.

Atkinson (1988) found out that cleanliness, security, value for money and courtesy of staff determine the customer satisfaction. Knutson (1988) revealed that room cleanliness and comfort, convenience of location, prompt service, safety and security, and friendliness of employees are important. Barsky and Labagh (1992) stated that employee attitude, location and rooms are likely to influence the travellers' satisfaction. A study was done by Akan (1995) showed that the main determinants of hotel guest satisfaction are the behavior of employees, cleanliness and timeliness. Choi and Chu (2001) concluded that staff quality, room qualities and value are the top three hotel factors that determine the travellers' satisfaction. 
Offering services to those customers preference is a starting point for providing the customer satisfaction. A relatively easy way to find out what type of services the customer prefers simply to ask them. According to Gilbert and Horsnell (1998), and Su (2004), guest comment cards (GCCs) are most commonly used for determining the hotel guest satisfaction. GCCs are usually distributed in the hotel rooms, at the reception desk or in some other visible place. However, studies reveals that numerous hotel chains use the guest satisfaction evaluating methods based on inadequate practices to make important and complex managerial decisions (Barsky, 1992; Barsky and Huxley, 1992; Jones and Ioannou, 1993, Gilbert and Horsnell, 1998; Su, 2004). The most commonly made faults are divided into three main areas, namely, quality of the sample, design of the GCCs, and the data collection and the analysis (Gilbert and Horsnell, 1998). In order to improve the validity of the hotel guest satisfaction measurement practice, Barsky and Huxley (1992) proposed a new sampling procedure "quality sample".

It reduces the non-response of bias by offering incentives for completing the questionnaires. The components of their questionnaire are based on disconfirmation paradigm and expectancy-value theory. In this manner, guests can indicate whether the service is above or below their expectations and whether they consider a particular service is important or not. Furthermore, Gilbert and Horsnell (1998) developed a list of criteria for GCC content analysis, which is adopted in this study. Schall (2003) discusses the issues of question clarity, scaling, validity, survey timing, question order and sample size.

\section{SERVICE QUALITY}

Service Quality is a multifaceted, elusive, subjective and abstract concept. It means different things to different people. The most common definition of the service quality is the comparison customers make between their expectations and perceptions of the received service (Parasuraman et al., 1988; Grönroos, 1982).

Quality is a multi-dimensional concept. Lehtinen (1982) defined three dimensions of the service quality, namely, physical quality, interactive quality and corporate quality. Similarly, Grönroos (1984) argued that service quality comprises of technical quality, functional quality and corporate image.

Additionally, Parasuraman et al. $(1985 ; 1988)$ developed the SERVQUAL scale, which became the most popular instrument for measuring the service quality. They identify five key dimensions of the service quality - reliability, tangibles, responsiveness, assurance and empathy. The SERVQUAL scale consists of 22 items for assessing the customer perceptions and expectations regarding the quality of service. A level of agreement or disagreement with a given item is rated on a seven-point Likert Scale. These results are used to identify the positive and negative gaps. These gaps are measured by the difference between the perceptions and the expectations scores and it implies the level of the service quality. If the result is positive, perceived customer service exceeds expected service. A negative result ensures that low quality of service. According to this instrument, the service quality reaches when perceived service meets or exceeds customer's expectations.

The SERVQUAL instrument is broadly used in a variety of service industries, including tourism and hospitality. Research related to this sector is divided into measuring the service quality in historic houses (Frochot and Hughes, 2000), hotels (Douglas and Connor, 2003; Antony et al., 2004; Juwaheer, 2004; Marković, 2004; Nadiri and Hussain, 2005; Olorunniwo et al., 2006; Wang et al., 2007), restaurants (Heung et al., 2000; Fu and Parks, 2001; Namkung and Jang, 2008), travel agencies (Atilgan et al., 2003; Martinez Caro and Martinez Garcia, 2008), diving (O'Neill et al., 2000), health spas (Snoj and Mumel, 2002; Marković et al., 2004; González et al., 2007), ecotourism (Khan, 2003), theme parks (O'Neill and Palmer,2003), tourism and hospitality higher education (Marković, 2005; Markovi ć, 2006). The instrument is used to measure hotel employee quality as well (Yoo and Park, 2007).

It's important to state that the service quality and the customer satisfaction are distinct concepts, although they are closely related. According to some authors, the satisfaction represents an antecedent of the service quality (Carman, 1990; Bolton and Drew, 1991). In this sense, satisfactory experience may affect the customer attitude and his or her assessment of the perceived service quality. Thus, satisfaction with a specific transaction may result with positive global assessment of service quality. Other authors argue that the service quality is antecedent of the customer satisfaction (Churchill and Suprenant, 1982; Anderson et al., 1994; Oliver, 1997; Oh, 1999; Zeithaml and Bitner, 2003; Jamali, 2007). This group of authors suggests that the service quality is a cognitive evaluation, which may lead to satisfaction. For this reason, the customer satisfaction is the result of the service quality.

On conclusion the relationship between quality and satisfaction is complex. Various authors portray it as Siamese twins (Danaher and Mattsson, 1994; Jamali, 2007). Although there still remain a lot of unresolved questions, it is to sum up that the service quality and the customer satisfaction can be perceived as separate concepts that have causal ordering.

\section{CONTENT ANALYSIS}

The Content analysis is an observational research method that is used to systematically to evaluate the symbolic content of all forms of recorded communications (Kolbe and Burnett, 1991). It provides scientific, objective, quantitative and generalisable description of the content.

Content analysis can be performed virtually on any medium with verbal and/or visual content - printed material, radio and television programs, recorded meetings, movies, songs, etc. It is extensively used in marketing and consumer behaviour research (Kassarjian, 1977; Wheeler, 1988; Sayre, 1992; Guthrie and Abeysekera, 2006).

The crucial technique of content analysis entails counting the number of times pre-defined categories of measurement appear in a given content. An effective content analysis should meet several requirements (Kassarjian, 1977; Guthrie and Abeysekera, 2006). First, a representative, randomly drawn 
sample should be selected. Second, the units of measurement, that is, the criteria of analysis must be clearly defined. These units can be specific a word, phrase, theme, paragraph, symbols, pictures, tables, or simply the existence or nonexistence of some event or claim.Third, data categorization must be systematic. It must be clear that an item either belongs or does not belong to a particular category. Finally, statistical analysis and interpretation of data are conducted.

Reliability and validity of the instrument and collected data be supposed to be demonstrated. Krippendorff (1980) identified three types of reliability for the content analysis, namely, stability, reproducibility and accuracy. Reliability can be achieved by several coders (judges) for processing the same content. Discrepancies between them should be minimal. Another factor to consider is the reliability of the coding instrument, which reduces the need for multiple coders. On the other hand, validity is defined as the extent to which an instrument measures what it is intended to measure. In the field of content analysis, choice of categories and content units enhance or diminish the likelihood of valid inferences (Kassarjian, 1977).

To achieve this goal "Customer Satisfaction" would be impractical unless Hotel Managers carry out a periodical assessment on their customer satisfaction and the quality improvement which are the focus of the present study. Therefore, this study focuses on the customer satisfaction of two 4-star hotels in Isfahan (Aseman (A) and Aliqapoo (B) ) chosen as the two sample hotels, on the basis of SERVQUAL model.

\section{Factors Influencing on Customer's Expectations}

The following are the recognition of the factors, which influence customer's expectations, can help the service providers to apply the appropriate procedures to modify the customer's expectations and to provide the customers with the service proportion to thereof. During their study on the customer's comments, "Parasuraman et al,, 1990" mentioned four key factors in shaping the customers' expectations.

1. Word-of-Mouth: Word of Mouth is a most widely used tool to identify the customer's expectations and it is very easy to communicate with others.

2. Personal Needs: The next factor is that to a certain level modifies the customer expectations is obtained as a result of particular situations and requirements and is called "Personal Needs". These needs are based on the customer physical, moral and mental states, which are greatly, influences other people and are oriented by the latter.

3. Prior Experiences: The past experiences on different situations helps the customers of negotiable paper offering enterprises it appears that the customers with high experience and have lower expectations about agents' modes of behavior, i.e. polite and close attitude; but instead, they have higher expectation on their efficiency, mastery and competence.

4. Advertisement and External Communications: Final factor which plays a key role in shaping the customer expectations is called external communications. These communications contain all direct and indirect messages sent from service providers to the customer. For example a publicity poster of a bank illustrates the friendly attitude of cashiers and/or a publicity brochure assuring the transcendental services of an enterprise are regarded.

One of the most important factors which of course belong to supplier's external communications collection is service cost or price. This factor plays a significant role in shaping the customer's expectations and especially those of organization future customers.

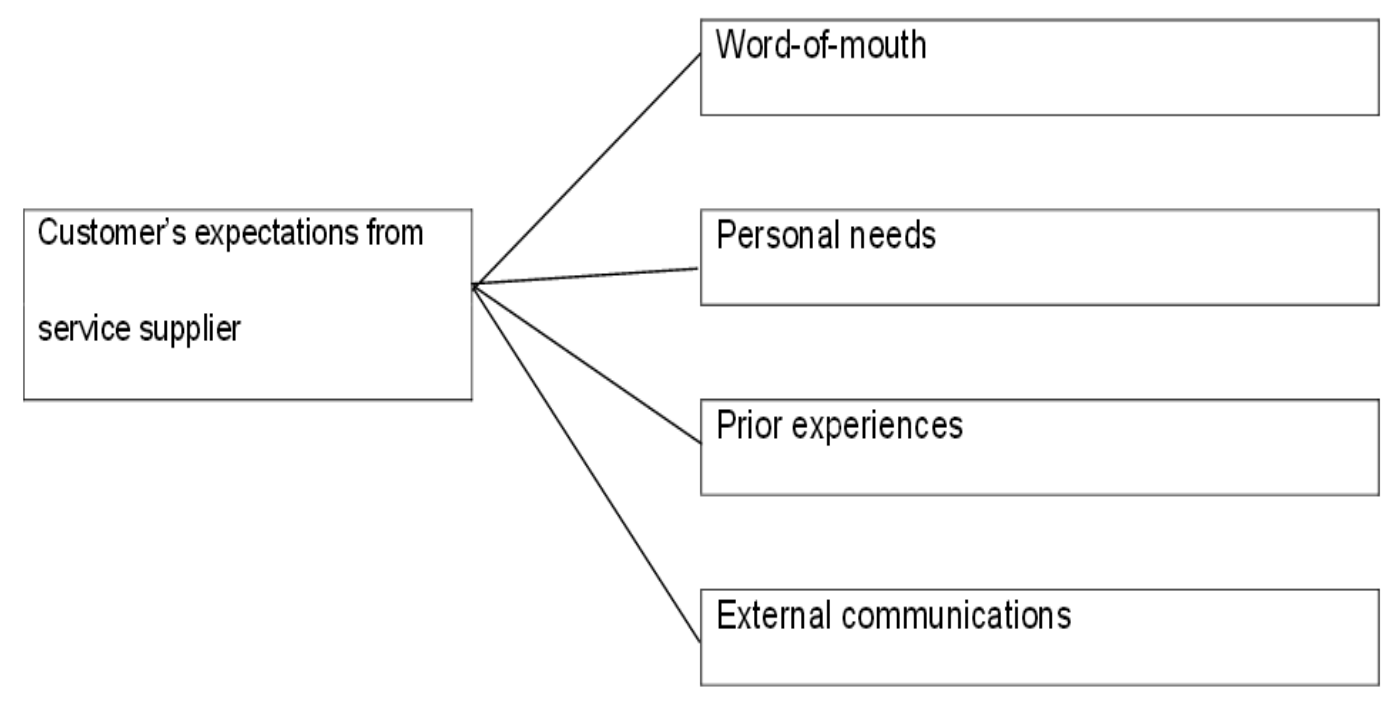




\section{Role of Managers in the Service Quality}

The initial conceptual model on the Service Quality was developed by Gronroos to enhance understand the Consumers' Service Quality perceptions and the factors that influence those perceptions. According to the model, the consumers' perceptions of the service quality results from an evaluation process, in which consumers' expectations are compared with their perceptions of the service actually delivered (Mangold \& Emin, 1990).

It is recommended that managers need to understand the types of the service quality factors for their own service(s) and understand their various relationships between perception and performance in order to design, measure and control their service. Service levels need to be set and strategies devised that first it recognizes the relative impact of individual factors on overall perceptions and secondly, link them to the organization's quality strategy (Johnston \& Heineke, 1996).

Furthermore, when decision makers in service organist ions, such as banks and hospitals are asked what constitutes quality in their services, the answers are less well-defined and tend to vary more from individual to individual. Consequently, the measurement, monitoring and Improvement of quality is an elusive task in many service organizations. While the concept of the service quality is difficult to define, the fact is, that both consumers and service providers evaluate the service quality on a daily and revolving basis (Mangold \& Emin, 1990)

\section{Attributes of Hotel Business}

The research in the hotel focuses on the relationship between the Customer's Satisfaction and the Service Quality of services and facilities. On the account of intangibility, inseparability, variability, and perishability of services, consumers' perception of satisfaction criteria may include contextual cues that they use to evaluate the service quality and to make the decisions about future patronage, whether or not they experienced the hotel's products and services before (Bitner, 1990; Parasuraman etal., 1985). Alpert (1971) and Kivela (1996) viewed the consumer products and services as a bundle of attributes, or features, and benefits; and stated that those attributes that directly influence the consumer choice are termed "determinant" attributes. These attributes, which could be different from those of competitors' offerings, may be the key factors in determining the consumers' intentions regarding future purchases. Wuest et al. (1996) defined perceptions of the hotel attributes as the degree to which travellers find various services and facilities important in promoting their satisfaction with hotel stays.

There are numerous studies of the needs and distinctiveness of travellers. The various reviews highlights that most travelers would consider the following hotel attributes when making a hotel choice decision: cleanliness, location, room rate, security, service quality and the reputation of the hotel or chain. Atkinson (1988) found that cleanliness of accommodation, followed by safety and security, accommodation value for money, and courtesy and helpfulness of staff are the top attributes for travelers in the hotel choice selection.

\section{RESEARCH METHODOLOGY}

Research Methodology normally depends upon the objectives, nature of the concept taken for the study and relevant implementing facilities. In other word, the purpose of the selection of research methodology is to select a method to find the answer/answers the question/questions of the research quicker and more exactly and easily. The research methodology used in this research is Descriptive-measuring of field study type. Descriptive method is used for review of literature and the subdivisions of descriptive method; the measuring method is used for the study of distribution and specifications of statistical sample, determining the nature of conditions and the relations between the events.

\section{Sampling Technique}

Since populations are so enormous geographical size and extents that researcher cannot refer to the all of populations, they select a sample of population and generalize the relevant results to the population studied. A sample means some members of a society with the particulars similar to the particulars of the society who represents the society and is homogenous with other members. In this study the researcher has applied the attribute random sampling method. The researcher has fixed 288 customers (guests) and they were selected randomly.

\section{Data Collection Method}

In this research, secondary data are collected from books, papers, journals and websites. For collecting the fresh hand data that is primary data the researcher has used structured questionnaire were used.

\section{Tools for Data Analysis}

In this research, the data are analyzed using descriptiveinferential statistics and SPSS (Statistical Package for Social Science).

\section{Data Analysis and Interpretation}

Table 1: Awareness about Restaurants

\begin{tabular}{|l|l|}
\hline Mode & Number of Customers \\
\hline Radio & 9 \\
\hline Television & 45 \\
\hline Newspaper & 30 \\
\hline Publicity & 40 \\
\hline Word of Mouth & 80 \\
\hline Friends & 25 \\
\hline Relatives & 29 \\
\hline Others & 30 \\
\hline Total & 288 \\
\hline
\end{tabular}




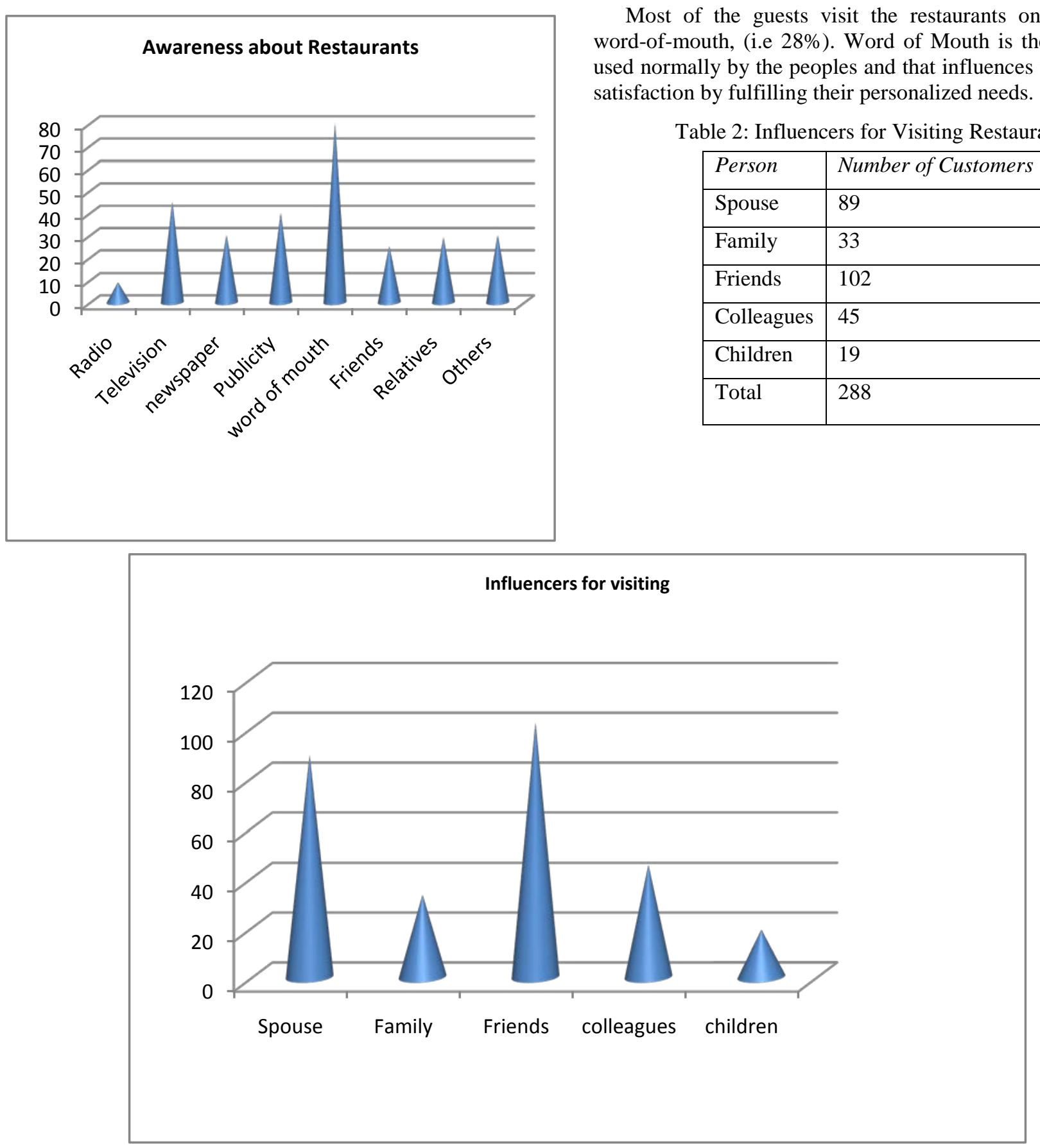

Majority of the respendents i.e 35\% are influenced by the Friends rather than any other source. This clearly replicates where they already experineced and by the attainment of that friends play a vital role in taking the guests to the hotel satisfaction they refer their friends too.

Table 3: Waiting Time

\begin{tabular}{|l|l|}
\hline Time & Number of Customers \\
\hline$<3$ mins & 167 \\
\hline $3-5$ mins & 54 \\
\hline $5-7$ mins & 22 \\
\hline $7-10$ mins & 30 \\
\hline$>10$ mins & 15 \\
\hline Total & 288 \\
\hline
\end{tabular}




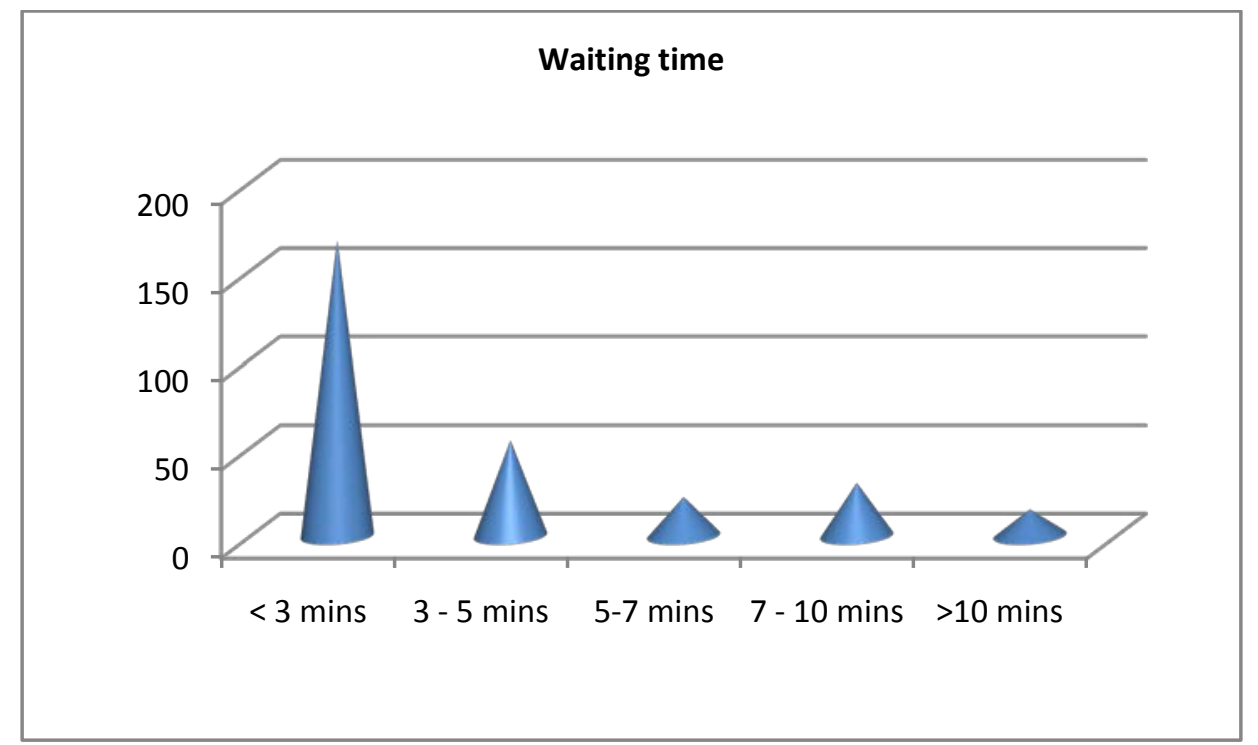

Almost 58\% of the customers responded that their waiting time is $<3$ minutes and this highlights the fact that the service providers are taking initiatives to meet the customer demand in time thereby maintain their SERVQUAL. In the attainment of the desired goal of the guests they can retain the customers, which in turn can bring new customers also.

Table 4: Opinion towards Neatness and Cleanliness

\begin{tabular}{|l|r|r|r|r|r|r|r|r|}
\hline Opinion & Vessels & Table & Floor & Waiter & Napkin & Wash Area & Drinking Water & Furniture \\
\hline HS & 25 & 10 & 103 & 50 & 140 & 80 & 78 & 69 \\
\hline S & 75 & 50 & 89 & 120 & 60 & 107 & 90 & 89 \\
\hline M & 119 & 110 & 60 & 43 & 30 & 66 & 90 & 43 \\
\hline DS & 54 & 88 & 30 & 50 & 20 & 20 & 12 & 48 \\
\hline HDS & 15 & 30 & 6 & 25 & 38 & 15 & 18 & 39 \\
\hline Total & 288 & 288 & 288 & 288 & 288 & 288 & 288 & 288 \\
\hline
\end{tabular}

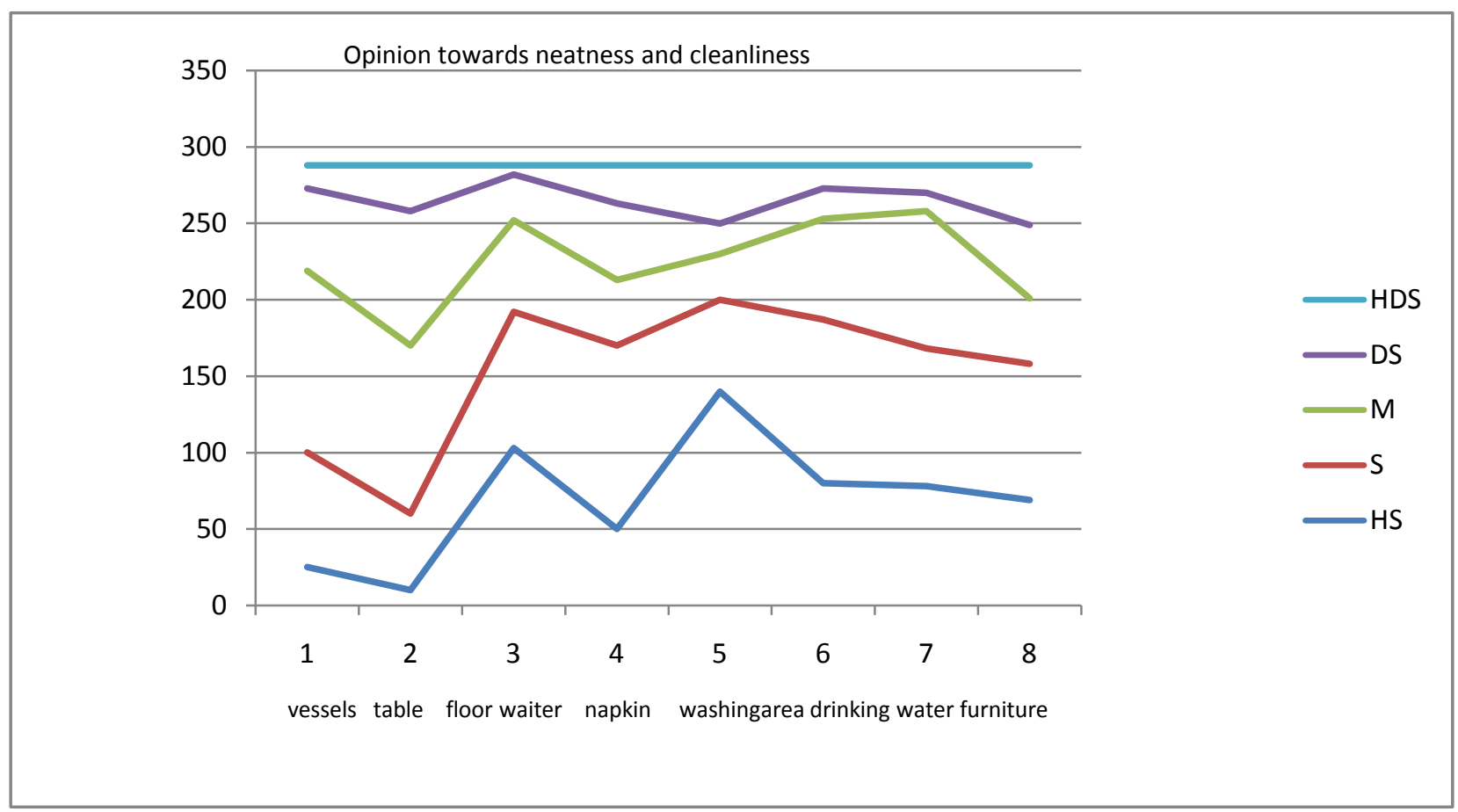

It is identified from the above analysis that customer opinion towards neatness and cleanliness with respect to vessels, wash area, drinking water, table, floor, waiter, napkin and furniture is above satisfactory level. This analysis once again replicates that the several precautionary measures have been taken by the service providers to hold the customer by providing quality food in a hygienic way. 
Table 5: Food Preferences

\begin{tabular}{|l|l|}
\hline Type of Food & Number of Customers \\
\hline South & 57 \\
\hline North & 34 \\
\hline Chinese & 69 \\
\hline Tandoori & 29 \\
\hline Continental & 84 \\
\hline Others & 15 \\
\hline Total & 288 \\
\hline
\end{tabular}

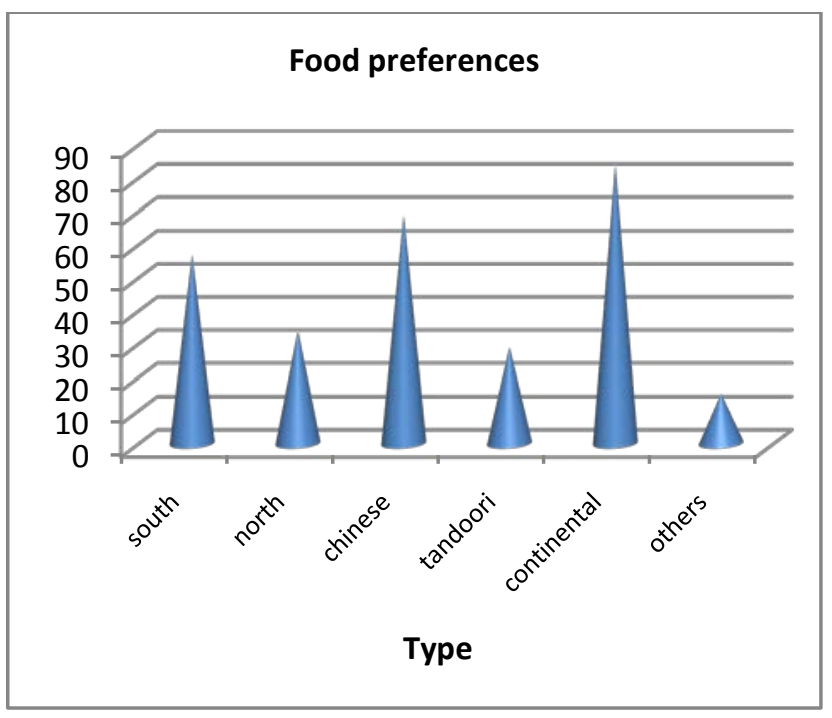

From the above data, it is inferred that $29 \%$ of the customers are willing to have Continental food, followed by Chinese and South-Indian foods. This analysis reveals that customers choose hotels to have variety of foods rather than the normal routine food and the service providers offer different varieties of food to attract and retain customers.

\section{Chi-Square Test}

Chi-square test is a statistical tool widely used to compare the observed data with data expected to obtain according to a specific hypothesis and to determine the "goodness to fit" between the observed and expected. It helps to identify the deviations are due to the result of chance or due to other influencing factors.

Chi square Test based on Income Level

\begin{tabular}{|l|l|l|l|l|}
\hline Observed Frequency & & & & \\
\hline Frequency of Visit & $<1$ lakh & $1-2$ lakhs & $2-3$ lakhs & $>$ 3 lakhs \\
\hline Once & 35 & 39 & 55 & 25 \\
\hline Twice & 9 & 14 & 17 & 30 \\
\hline More than twice & 5 & 16 & 19 & 24 \\
\hline
\end{tabular}

\begin{tabular}{|l|l|l|l|l|l|}
\hline $\begin{array}{l}\text { Expected } \\
\text { Frequency }\end{array}$ & & & & & \\
\hline $\begin{array}{l}\text { Frequency of } \\
\text { Visit }\end{array}$ & $<1$ & $\begin{array}{l}1-2 \\
\text { lakhs }\end{array}$ & $\begin{array}{l}2-3 \\
\text { lakhs }\end{array}$ & $\begin{array}{l}>3 \\
\text { lakhs }\end{array}$ & $\begin{array}{l}\text { Chi - } \\
\text { square }\end{array}$ \\
\hline Once & 38 & 35 & 47 & 40 & 0.000584 \\
\hline Twice & 3 & 18 & 17 & 40 & 0.000051 \\
\hline More than Twice & 2 & 6 & 11 & 24 & 0.0001357 \\
\hline Chi value & & & & & 0.000777 \\
\hline
\end{tabular}

$\mathrm{H}_{0}$ : There is no significant relationship between income level of the Guests(Customers) and their frequency of visit to the restaurants.

$\mathrm{H}_{1}$ : There is significant relationship between income level of the Guests (Customers) and their frequency of visit to the restaurants.

It is found from the above analysis that p-value is less than 0.05 hence reject the null hypothesis. So, it concludes that there is significant relationship between income level of the Guests and their frequency of visit to the restaurants. It is clear from this test that income level of the customer has high impact on the frequency of visits to the restaurant i.e., high income level customers visits the restaurant more number times in a month rather than the less income level of customers. So income plays a crucial role towards the customer's intention in determining the frequency of visit to the restaurant.

\section{CONCLUSION}

This research can provide an outlook to the operators of the restaurants fix the scale for assessing the customer satisfaction by identifying the changing customer perception; thereby can modify their tool for assessing. This study unites the analysis of customer satisfaction management schemes and the content analysis in the hotels. This study finding is mostly reliable mostly with similar studies conducted by Gilbert and Horsnell (1998), Su (2004) and Mumel and Snoj (2007). On conclusion the efficiency of the customer satisfaction measurement depends on the measurement methodology used to determine. On understanding the customer's preference and attitude the Hotel operators can provide benchmarking features to attract the customers by providing Quality of food and also by taking tremendous effects to retain the customer in longevity.

\section{REFERENCES}

[1] P. Akan, "Dimensions of service quality: a study in Istanbul”, Managing Service Quality, Vol. 5, No. 6, Pp. 39-43, 1995.

[2] E.W. Anderson, C. Fornell and D.R. Lehmann, "Customer Satisfaction, Market Share and Profitability”, Journal of Marketing, Pp. 53-66, 1994.

[3] J. Antony and F.J. Antony, "Evaluating service quality in a UK hotel chain: a case study", International Journal of Contemporary Hospitality Management, Vol. 16, No. 6, Pp. 380-384, 2004.

[4] E. Atilgan, S. Akinci and S. Aksoy, "Maping service quality in the tourism industry”, Managing Service Quality, Vol. 13, No. 5, Pp. 412422, 2003.

[5] A. Atkinson, "Answering the eternal question: what does the customer want?", The Cornell Hotel and Restaurant Administration Quarterly, Vol. 29, No. 2,Pp. 12-14, 1988.

[6] J.D. Barsky, "Customer Satisfaction in the Hotel Industry: Meaning and Measurement”, Hospitality Research Journal, Vol. 16, No. 1, Pp. 51-73, 1992.

[7] J.D. Barsky, World - Class Customer Satisfaction, Richard D. Irwin, Inc, 1995.

[8] J.D. Barsky and S. J. Huxley, "A Customer-Survey Tool: Using the Quality Sample", The Cornell Hoteland Restaurant Administration Quarterly, Vol. 33, No. 6, Pp. 18-25, 1992.

[9] J.D. Barsky and R. Labagh, "A strategy for customer satisfaction", The Cornell Hotel and Restaurant Administration Quarterly, Vol. 35, No. 3, Pp. 32-40, 1992.

[10] R.N. Bolton and J.H. Drew, "A multi-stage model of customers' assessments of service quality and value”, Journal of Consumer Research, Vol. 17, Pp. 375-384, 1991. 
[11] R.N. Cardozo, “An experimental study of customer effort, expectation and satisfaction”, Journal of Marketing Research, Vol. 2, Pp. 244-249, 1965.

[12] X. Luo and C. Homburg, "Neglected Outcomes of Customer Satisfaction”, Journal of Marketing, Vol. 71, No. 2, Pp. 133-149, 2007.

[13] S. Marković, "Measuring Service Quality in Croatian Hotel Industry: A Multivariate Statistical Analysis", Our Economy, Pp.27-35, 2004.

[14] S. Marković, "Perceived service quality measurement in tourism higher education: Case study of Croatia”, Tourism Today, Pp. 91-109, 2005. 